\title{
Coupling Numerical Simulation and Machine Learning to Model Shale Gas Production at Different Time Resolutions
}

\author{
Amirmasoud Kalantari-Dahaghi*, California Resources Corp. (CRC) \\ E-mail: akalanta@mix.wvu.edu ; Amirmasoud.KalantariDahaghi@CRC.com \\ Soodabeh Esmaili, California Resources Corp. (CRC); E-mail: Soodabeh.Esmaili@CRC.com \\ Shahab Mohaghegh, West Virginia University; E-mail: Shahab.Mohaghegh@mail.wvu.edu
}

\begin{abstract}
Reservoir simulation is the most robust tool for simulating gas production from the desorption controlled and hydraulically fractured shale reservoir. Incorporation of the created massive hydraulic fractures explicitly into the simulation model is the major challenge during the model development and computation phases.
\end{abstract}

A pattern recognition-based proxy model is our proposed technique to overcome the aforementioned problem by modeling time successive shale gas production at the hydraulic fracture cluster level at different time resolutions (Short-, medium- and long term). Ensemble of multiple, interconnected adaptive neuro-fuzzy systems create the core for the development of the shale proxy models. In this approach, unlike reduced order models, the physics and the space-time resolution are not reduced. Instead of using pre-defined functional forms that are more frequently used to develop response surfaces, a series of machine learning algorithms that conform to the system theory are used.

A history-matched Marcellus shale gas pad with six horizontal laterals and 169 clusters of hydraulic fracture is used as a base case for shale proxy model development. Additionally, several realizations are defined in order to capture the uncertainties inherent in the shale simulation model. The proxy model is validated using a blind simulation run that is not used during the model development process. The developed shale proxy model re-generates the simulation results for methane production for 169 clusters hydraulic fracture in a second with high accuracy $(<15 \%$ error), thus making a comprehensive analysis of production from shale a practical and feasible option. Moreover, it can be used as an assisted history-matching tool, since it has the capability to scrutinize the solution space and produce the model response to the uncertainty changes very fast.

\section{Introduction}

Numerical Modeling of Shale Gas Reservoirs- Modeling gas-matrix-fracture phenomena and developing reliable and fast reservoir assessment techniques play very important role to fulfill the fast development plan for shale assets. Production optimization and reserves estimation in shale formation can be achieved through advanced completion technology and numerical reservoir simulation.

Dual continuum models are the conventional method for simulating fractured systems and are widely used in the industry (Figure 1).Barenblatt et al. (1960) and Warren-Root (1963) first developed mathematical models describing the fluid flow in dual-porosity media. These models assume single-phase fluid in pseudo-steady-state, transfer from matrix to fracture. The Single phase-Warren and Root approach was extended to the multiphase flow by Kazemi (1969), Rossen (1977), and deSwaan (1976) and Saidi (1983) and the dual porosity simulators were developed, which were capable of modeling unsteady state or transient fluid transfer between matrix and fracture. In this model, naturally fractured media was represented as a set of uniform matrix blocks and fractures. 


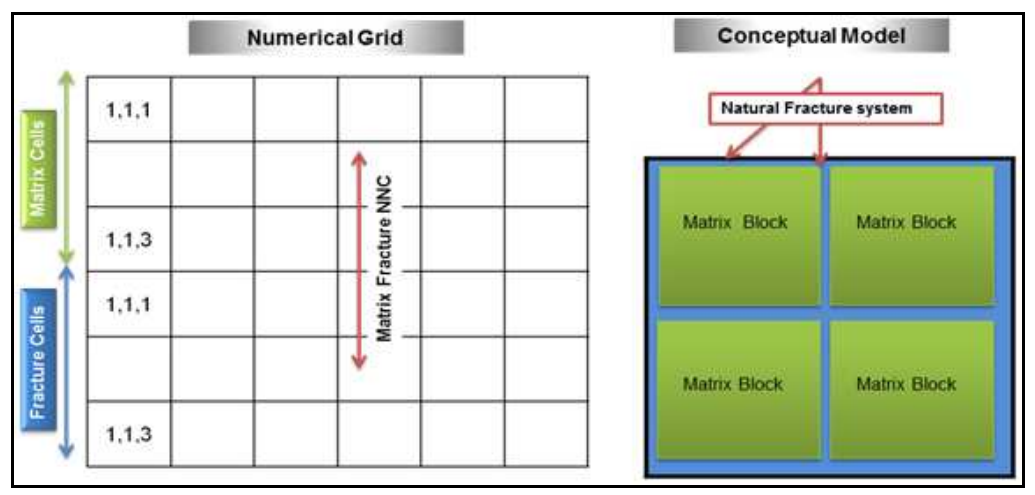

Figure 1. Dual porosity numerical and conceptual model

Later, Blaskovich et al. (1983), Hill et al. (1985), and Dean et al. (1986) developed dual permeability models, which allow for matrix to matrix and fracture-to-fracture flow and can be used to model transient gas production from hydraulic fractures in shale gas reservoirs (Rubin, 2010; Cipolla et al., 2010).

Dual-Mechanism approach (Darcy flow and Fickian diffusion occur parallel in matrix) was introduced to characterize the gas flow in coal or shale formations through the dynamic gas slippage factor (Ertekin, et al., 1986; Clarkson, et al., 2010).

Javadpour (2009) first derived the concept of apparent permeability considering the Knudsen diffusion, slippage flow and advection flow, and it was further applied to pore-scale modeling for shale gas (Shabro et al.,2011 and Shabro et al.,2012). Based on a unified Hagen-Poiseuille-type formula, Beskok et al. (1999), Civan et al. (2010) and Ziarani et al.(2012) proposed a method to calculate apparent permeability using the flow condition function and the intrinsic permeability of porous media. Yan et al. (2013) believed that the validity of this latter model for different flow regimes still requires further confirmation. However, even with this greater detail, these models may not be sufficient due to the use of an undivided shale matrix.

Even with a proper connectivity between different pore systems, there is still a little understanding of this aspect (Andrade et al., 2011). On the other hand, Hudson et al. (2011, 2012) categorized the shale reservoir into organic porosity, inorganic porosity, natural fractures and hydraulic fractures, and investigated several different tank models for connections between each pore system.

Unfortunately, the models to characterize the distribution of each continuum and the connections between those continua appear too regular to be realistic for shale reservoirs. Clearly, there remains a strong requirement to accurately model production from unconventional reservoirs based on detailed physics of the process and the interaction between two different porosities such that modeling uncertainty is reduced (Yen et al.2013).

Generally, shale gas development and production performance has several folds: 1.Understanding the complex physics at pore scale 2. Up-scaling the physics to reservoir scale 3. Modeling and incorporating the hydraulic fractures into the simulation model 4. Uncertainty analysis, history matching and forecasting the production.

Apart from the understanding the complex physics in shale reservoirs and trying to model that, the economic production of these completion-driven reservoirs are highly depends on the quality of the created massive multiple cluster hydraulic fractures and their interaction with the rock fabric. However, the modeling of shale reservoir becomes even more complicated with the existence of such complex fracture network.

The hydraulic fracturing field data (e.g. Proppant amount/size, slurry volume, injection pressure and rate, etc.) cannot feed the numerical models directly. For that reason, analytical and semi-analytical techniques can be used to model hydraulic fractures initiation and propagation and calculate the corresponding properties by taking into 
consideration the state of stress and geomechanics that can be used in a form of grid property in the reservoir simulation.

Explicit Hydraulic Fracture (EHF) modeling method, and the Stimulated Reservoir Volume (SRV) are two main approaches to implement the calculated hydraulic fracture characteristics to the numerical simulation, and each requires a proper gridding technique. Among these different approaches, EHF is the most complex way to model the effect of hydraulic fracturing on shale production with the numerical simulation. Despite complexity, this approach attempts to implicitly honor the hydraulic fracturing data at the cluster/stage level and incorporate such information in the simulation model.

Model setup for the EHF technique is long and laborious and its implementation is computationally expensive, such that it becomes difficult or in some cases impractical to model beyond a single pad. By reviewing the numerical reservoir simulation modeling efforts in the literature with focus on shale reservoirs, it can be noticed that almost all published studies are concentrated on the simulation of gas production from single shale wells (Cipolla et al., 2010, Meyer et al., 2010, Bazan et al., 2010, Samandarli et al., 2011, Chaudhri, 2012, Eshkalak et al., 2014 ). This confirms the complexity and computational prohibitively of using this technique specially in the case of performing simulation at multiple pad or full-field level.

Stimulated Reservoir Volume (SRV) is another/alternative technique for modeling the impact of created and propagated hydraulic fractures in shale formation. This approach was initially proposed when the extension and orientation of created hydraulic fractures can be calculated base on microcosmic events. This technique, make the simulation and modeling process simpler and much more faster, compared to the EHF method, by modeling the hydraulic fracture volumetrically with enhanced permeability region around the wellbore.

Numerous published papers addressed the geometry and shape of the SRV created around horizontal wellbores in shale reservoirs using micro-seismic monitoring techniques with simple diagnostic plots (Fisher et al.2002, Maxwell et al.2002, Daniels et al.2007). Most of these efforts had not been calibrated quantitatively by mathematical correlations to production data.

On the other hand, in most of the shale simulation studies, micro-seismic data is not available; therefore this approach can and has been miss-used to simplify the history matching process by only changing the permeability around the wellbore and without taking into account the hydraulic fracturing field data, which ultimately results in inaccurate forecast, even with achieving good history matching result. Therefore, in order to use the numerical simulation as a ground breaking tool for shale reservoir management, and necessity of properly incorporating hydraulic fractures by honoring the hydraulic fracturing hard data (measured at the field) in the model while having limited access to micro-seismic data, the EHF technique is a physically more accurate approach. The only problem exists here is to find a solution to improve the model development and simulation run time.

The objective of this study is to trying to address the aforementioned issues regarding the development and use of numerical simulation for modeling shale production behavior. Those issues are as follows:

1. Selecting a proper technique for incorporation of HF data in the simulation model.

2. Modeling a multilateral pad with massive hydraulic fractures instead of single lateral.

3. Honoring the hydraulic fracturing hard data (slurry volume, injection pressure, proppant size etc.) and properly incorporate such information in simulation model.

4. Maximizing the utility of the developed simulation model by reducing simulation turnaround time (development and run time).

\section{Simulation Model for a Multilateral Pad with Massive Hydraulic Fractures}

In order to build a pattern-recognition based proxy model, a detailed shale simulation model is developed using the information from 77 Marcellus shale gas wells in Pennsylvania with a total number of 652 stages of hydraulic fracture and 1893 clusters. The hydraulic fracture properties (e.g. hydraulic fracture half length, height, width and 
conductivity) are calculated for each individual cluster using fracturing job data (hard data) such as proppant amount/size, clean volume, slurry volume, injection pressure/rate, fluid loss , well trajectory, perforation, geomechanical properties and stress.

One of the pads (called WVU pad) with six horizontal laterals in the study area is selected to perform the history matching process. A dual porosity, with discretized matrix blocks and with the grid refinement to explicitly represent the hydraulic fracture, consisting of 200,000 grid blocks with three simulation layers in non-refined regions and nine simulation layers in the refined regions is developed. Logarithmic local grid refinement is performed and each host simulation cell is divided into seven grid blocks laterally and three vertically. The finest grid has $1 \mathrm{ft}$ width and represents the hydraulic fracture in the reservoir simulation model, which possesses the hydraulic fracture characteristics that are already calculated. History matching process is completed for all the WVU pad's laterals based on the three years of daily gas production. Figure 2 shows the entire study area with 77 horizontal wells and the location of the target WVU pad for history matching.

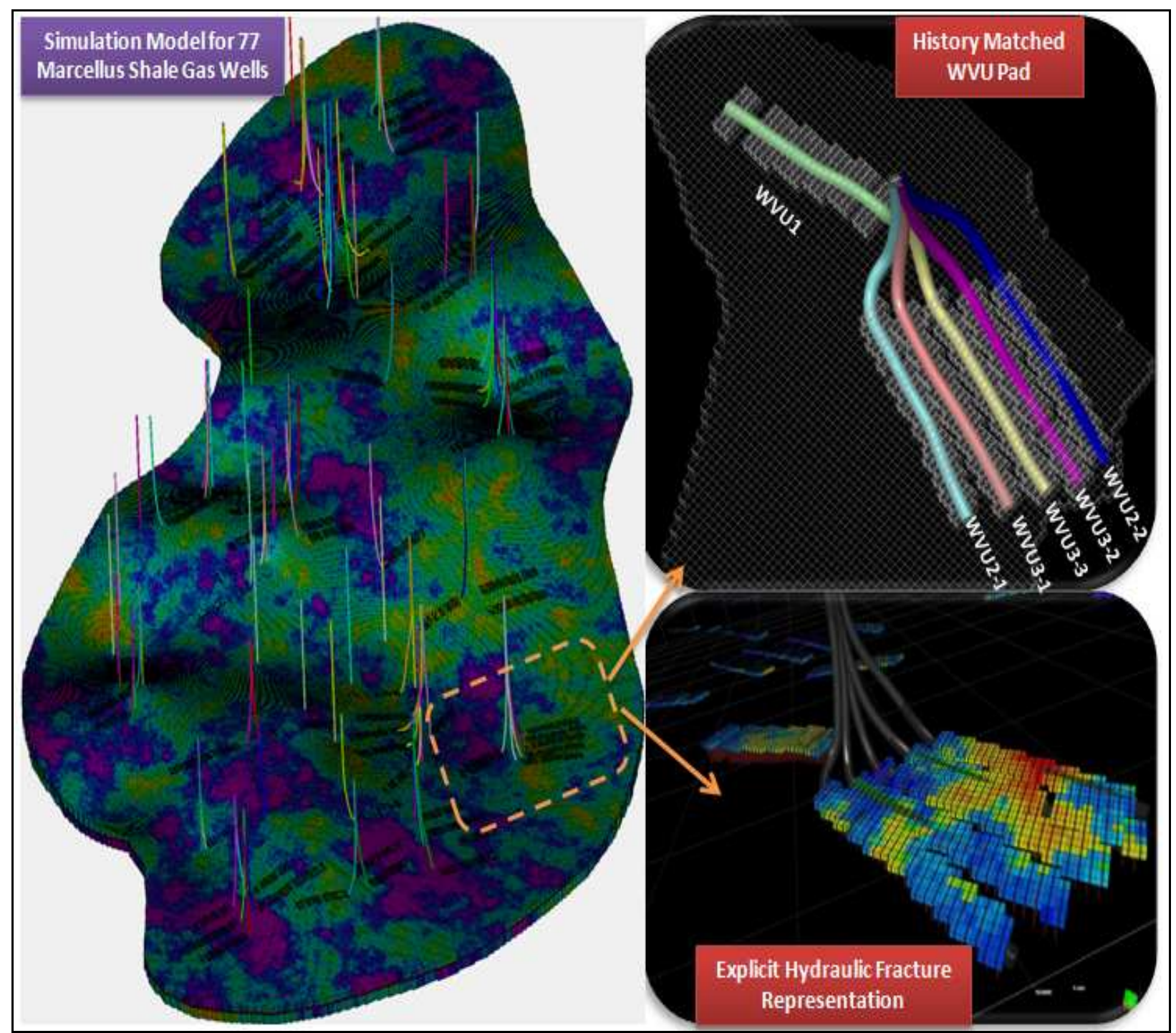

Figure 2. A 3-D view of the simulation model and configuration of the target WVU pad

As stated before, designing and running the simulation cases to model the production performance of multi lateral shale gas wells by applying Explicit Hydraulic Fracture modeling technique (EHF), is long and laborious and its 
implementation is computationally expensive thus requiring the development of a robust proxy model as a an alternative for fast track uncertainty analysis.

\section{Machine-learning for Shale Proxy Model Development}

\section{Background}

Proxy modeling is one of the most widely used methods to replicate the functionality of the detailed numerical simulation model and by assisting in the master development planning, quantification of uncertainties, operational design optimization, and history matching. Most frequent used proxy models in oil and gas industry are reduced models and response surfaces that reduces simulation run-time by approximating the problem and /or the solution space (Kalantari et al., 2012). Response surfaces that are essentially a statistic-based proxy models require hundreds of simulation runs in order to be used for uncertainty analysis and optimization purposes.

As stated by Mohaghegh (2014), there are two well-known problems that are associated with statistics, especially when it is applied to problems with well-defined physics behind it: a) Issue of "correlation vs. causality"b) Imposing a pre-defined functional form such as linear, polynomial, exponential, etc. to the data that is being analyzed. This approach will fail when data representing the nature of a given complex problem does not lend itself to a pre-determined functional form and it changes behavior several times.

Pattern recognition-based shale proxy model is our proposed technique as a next generation of proxy models, that it takes a different approach to building such model. In this approach, unlike reduced order models, the physics and the space-time resolution are not reduced and instead of using pre-defined functional forms that are more frequently used to develop response surfaces, a series of machine learning algorithms that conform to the system theory are used for training with ultimate goal of accurately impersonate the intricacy of a developed shale numerical reservoir simulation model.

Ensemble of multiple, interconnected adaptive neuro-fuzzy systems (Nauck, 1997; Jang, 1995) create the core for the development of these models. An artificial neural network is an information processing system with certain performance features analogous to biological neural networks. In this system, neurons are clustered into different layers including input, output and hidden layers. The number of parameters in the dataset defines the number of neurons in the input layer. One or multiple output/s can be defined during a neuro-model development. One important step toward building a proxy model with machine learning is feature extraction. This can be done by including the hidden layer and defining the hidden neurons in that layer, which increases the dimensionality that accommodates classification and pattern recognition.

Neural networks can be divided into two main classes based on the training algorithms, namely unsupervised and supervised. In the supervised training mode, both input and output in a form of a spatio-temporal database are presented to the neural network to permit learning on a feedback basis. Different clustering algorithms can be used for partitioning the cases into three main groups: Training, Calibration and Validation. During the training process, the weights between the processing elements are adjusted. Memorization and over-training are two main issues during the development of a Data-driven proxy models that must be avoided. The calibration portion is used for that purpose to examine the trained neural networks generalization capabilities. The proxy model development workflow is completed, once the verification dataset is used to test the predictive capability of the model.

\section{Methodology}

Inclusive spatio-temporal database generation is the starting point and the most important step toward building a pattern recognition-based proxy model. A comprehensive spatio-temporal dataset is generated by coupling the matrix, natural fracture properties and hydraulic fracture characteristics with desorption features as well as operational constraints, which are used in the numerical simulator as input data, with the calculated gas production rate from simulator. This database includes details of fluid flow in shale system that the pattern recognition-based proxy model needs to learn. The developed proxy model is then validated using blind simulation runs and then used for reservoir management and planning purposes. 
In order to make a comprehensive and more realistic database, in addition to the history-matched model, nine additional realizations are defined to fully capture the uncertainty domain for the study area (77 horizontal wells). The generated expert database is used for teaching highly non-linear and complex shale system behavior to the multilayer feed-forward back-propagation neural networks. The fully calibrated neural network is able to re-generate the numerical simulation output (production profiles) for all 169 clusters of hydraulic fractures for six horizontal laterals.

In order to fully capture the shale gas production behavior (i.e. changes in flow regime) as a function of time, three spatio-temporal databases for developing three pattern-recognition based proxy models at hydraulic fracture cluster level with different time resolutions are developed (Daily for the first two months, monthly for the first 5 years and yearly for 100 years of production). Figure 3 shows the detailed workflow for the pattern-recognition based shale proxy models development.

A complete list of inputs and corresponding ranges obtained from the histogram of distributed actual properties for 77 wells that are used for spatio-temporal dataset development is shown in Table 1. In order to consider the possible changes in operational constraints and include them in the database, ten different bottom-hole pressure profiles are designed with constant (200, 250, 300, 350 and 400 psi), increasing (from 150 to 550psi) and declining (from 2500 to $90 \mathrm{psi}$ ) trends.

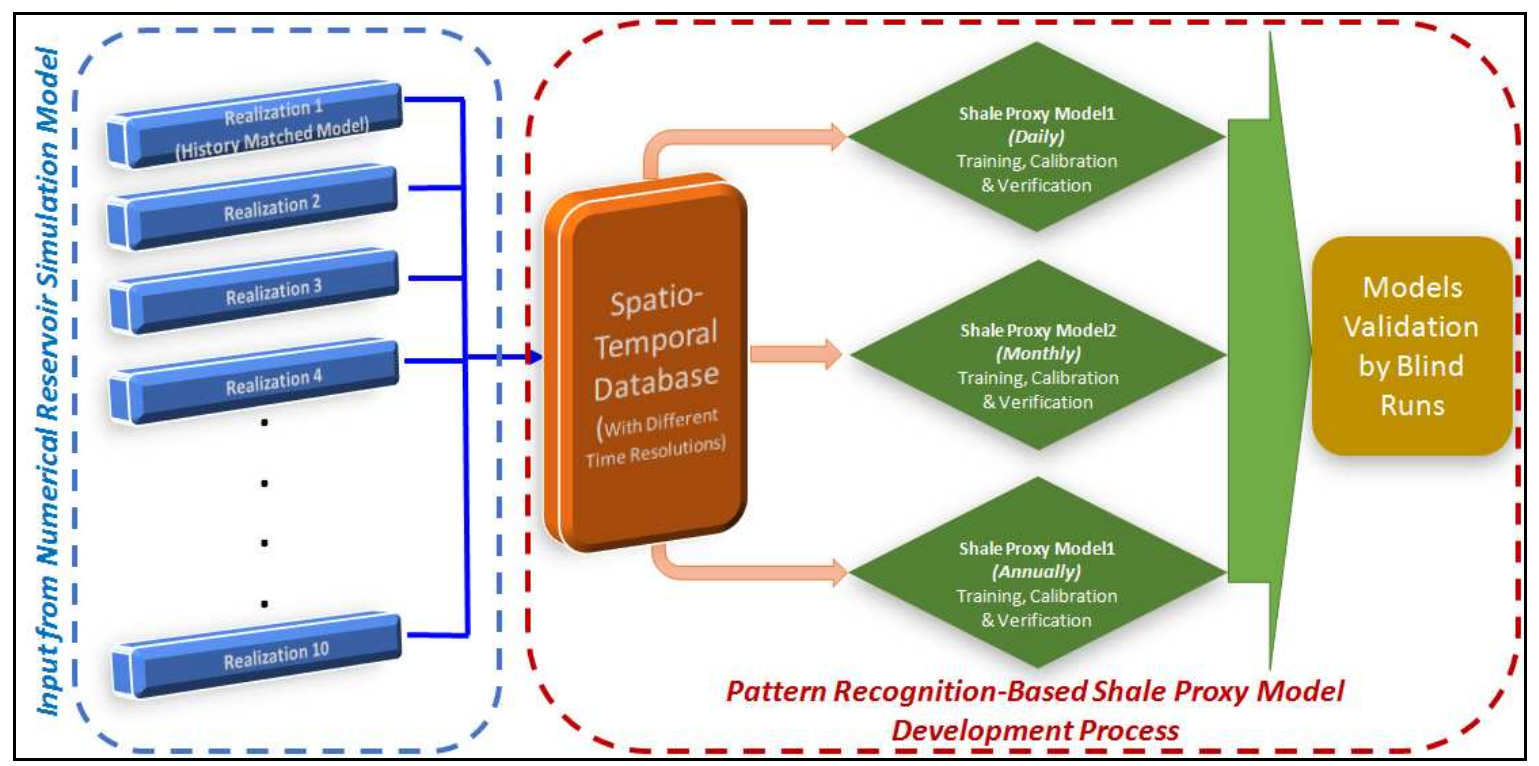

Figure 3.Pattern Recognition-Based Shale proxy model development workflow

Table 1.Main input data for Data-driven shale proxy models development

\begin{tabular}{|c|c|c|c|c|}
\hline $\begin{array}{c}\text { Matrix porosity } \\
{[0.054-0.135]}\end{array}$ & $\begin{array}{c}\text { Matrix permeability } \\
{[0.0001-0.00097(\mathrm{md})]}\end{array}$ & $\begin{array}{c}\text { Natural fracture } \\
\text { porosity } \\
{[0.01-0.04]}\end{array}$ & $\begin{array}{c}\text { Natural fracture } \\
\text { permeability } \\
{[0.001-0.01(\mathrm{md})]}\end{array}$ & $\begin{array}{l}\text { Sigma factor } \\
{[0.005-0.6]}\end{array}$ \\
\hline $\begin{array}{c}\text { Hydraulic fracture } \\
\text { height } \\
{[100-125 \mathrm{ft}]}\end{array}$ & $\begin{array}{c}\text { Hydraulic fracture } \\
\text { length } \\
{[200-1100 \mathrm{ft}]}\end{array}$ & $\begin{array}{c}\text { Hydraulic fracture } \\
\text { conductivity } \\
{[0.5-5.4(\text { md-ft) }]}\end{array}$ & $\begin{array}{c}\text { Rock Density } \\
{[100-180(\mathrm{lb} / \mathrm{ft} 3)]}\end{array}$ & $\begin{array}{c}\text { Net to Gross ratio } \\
{[0.75-0.98]}\end{array}$ \\
\hline $\begin{array}{l}\text { Longmuir volume } \\
\text { [40 -85 (scf/ton)] }\end{array}$ & $\begin{array}{l}\text { Longmuir pressure } \\
\text { [600-870 psi] }\end{array}$ & $\begin{array}{l}\text { Diffusion coefficient } \\
{[0.5-2.8(\mathrm{ft} 2 / \text { day })]}\end{array}$ & $\begin{array}{l}\text { Sorption time } \\
{[1-250(\text { day })]}\end{array}$ & $\begin{array}{l}\text { Initial Reservoir } \\
\text { Pressure } \\
\text { [3000-4288(psi)] }\end{array}$ \\
\hline
\end{tabular}


In each simulation run, each time step with corresponding static and dynamic information generates a unique case for the training and validation purposes. In order to take into account the impact of different grid blocks' properties on each cluster production a "Tiering system" is defined .Three different tiers are defined and a property for each tier is calculated by up-scaling the properties of all the grid blocks in the corresponding tier. Figure 4 (left) illustrates the Tiering systems and shows three types of tiers that are used in this study.

- Tier 1: Includes all the refined grid blocks for a target hydraulic fracture cluster.

- Tier 2(- and+): Covers the rest of grid blocks that are extended to the north (+) and south (-) of the tier 1, all the way toward the reservoir boundary or a hydraulic fracture from an offset lateral, both laterally and vertically.

- $\quad$ Tier 3(- and+): Covers the rest of grid blocks that are not covered by Tiers 1 and 2.

Additionally, the interference effect between the clusters can be captured by dividing them into four different classes based on their relative location. The following is the definition of each cluster type and the schematic is shown in Figure 4 (right).

- Type 1: This type of cluster has only one offset cluster that shares part of its drainage region.

- Type 2: The second type of cluster has two offset clusters causes the drainage area to be shared more than the type 1 .

- Type 3: Three neighboring clusters bound the third type thus; the drainage area will be shared more than type 1 and 2.

- Type 4: Four neighboring clusters bound the last type and drainage area will be shared more than the other types.

Tier System Definition

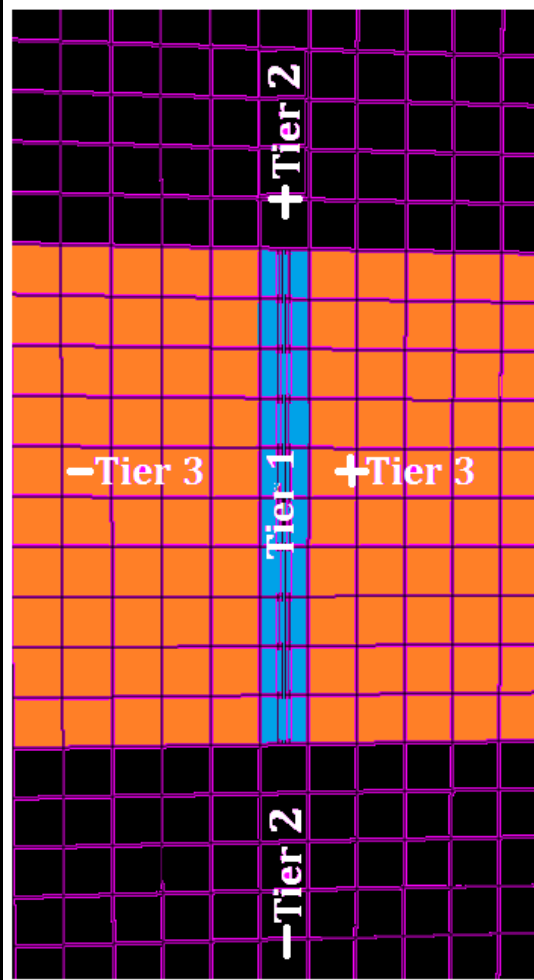

Cluster Type Definition

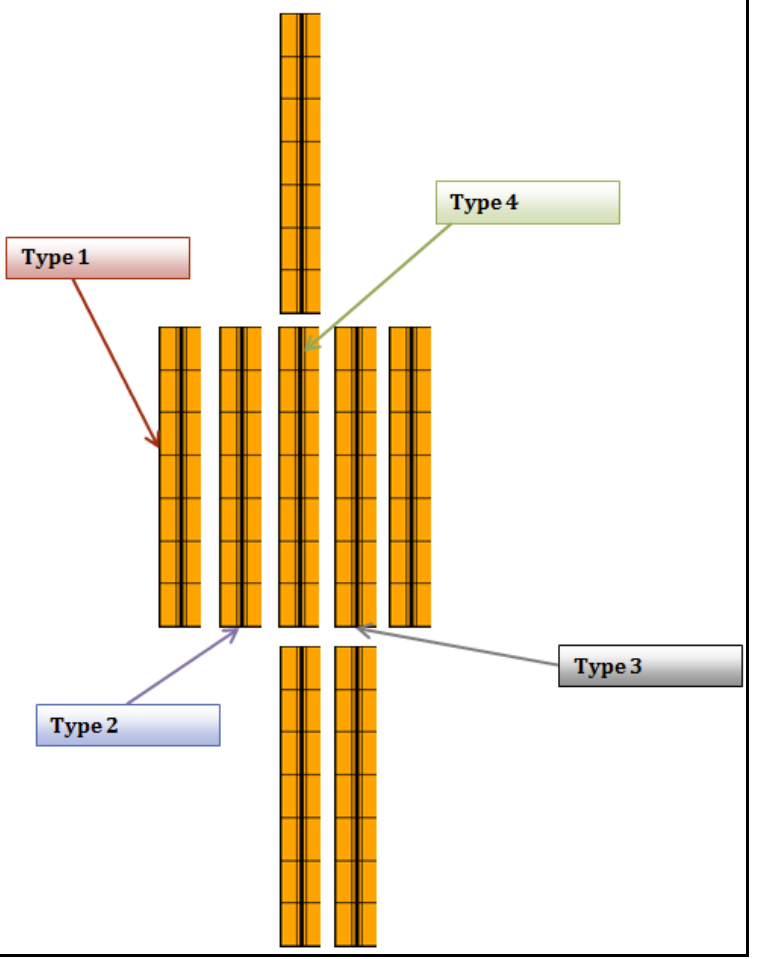

Figure 4.Tier system and cluster type definition (from left to right) 


\section{Results and discussion}

Three pattern recognition-based proxy models at hydraulic fracture cluster level with different time resolutions are developed. The first proxy model is designed to re-generate the simulation output for each cluster as well as entire lateral for the first two months of production with daily time steps (Mscf/day). The second one is developed to mimic the simulation results of methane production for the first five years of production on a monthly basis (Mscf/month). Finally, the last proxy is developed to predict the yearly gas production for 100 years (Mscf/year). Following is the details for each model and the results.

\section{First Pattern Recognition-based Shale Proxy Model (Daily-basis)}

1690 unique (169 clusters* 10 runs) production profiles with different reservoir properties, sorption attributes (sorption time and Langmuir isotherms), hydraulic fracture component, and operational constraints are generated to create a representative database with 98020 pairs of input-output. This dataset is used for training, calibration and validation of a multilayer feed-forward back-propagation neural network with 55 hidden neurons to perform pattern recognition in non-linear and multi dimensional problem.

During the training and validation process, the most prominent input parameters on daily gas production from shale are identified. According to this analysis, the hydraulic fracture conductivity and natural fracture permeability are among the most influential parameters for the first two months of production in the Marcellus shale. Moreover, as it is expected, the sorption time and the Langmuir pressure and Langmuir volume which, control the desorption, diffusion and adsorbed gas content of shale, have the minimal impact on the first two months of production.

The spatio-temporal database is partitioned with a $70 \%$ training $15 \%$ for calibration and $15 \%$ for verification. Figure 5 shows the cross plots for predicted and simulated values of daily gas production rate (Mscf/day) for training, calibration and verification steps (from left to right). In these plots, x-axis corresponds to the neural network predicted gas rate and the y-axis shows the simulated gas rate by reservoir simulator.

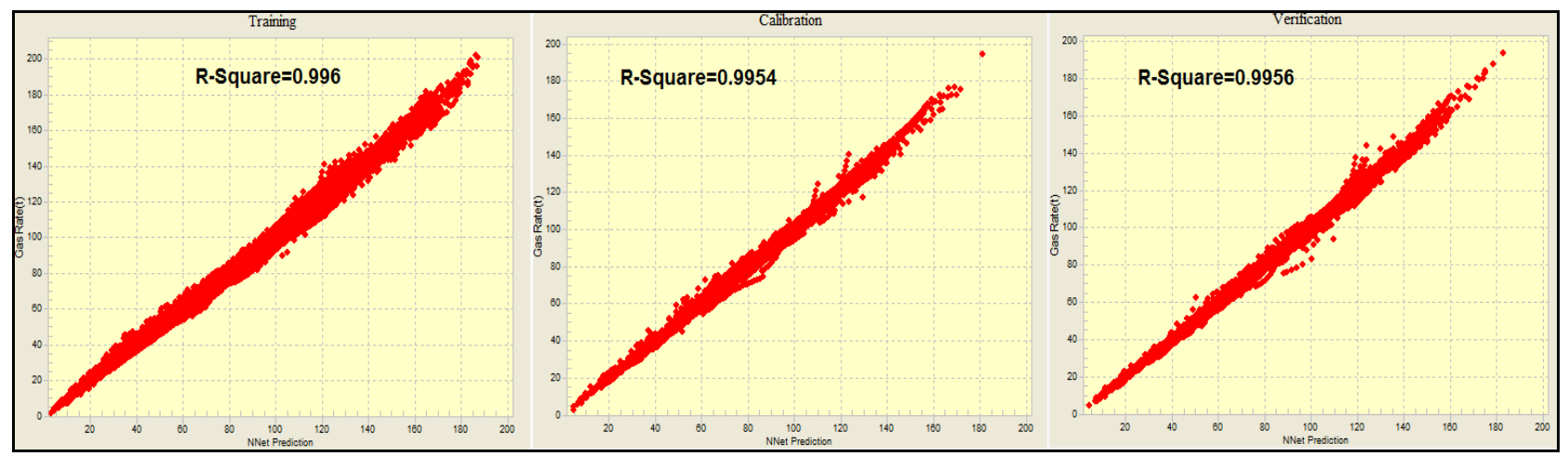

Figure 5 NN training, calibration and validation results (From left to right relatively) - Daily proxy model

The result with an $\mathrm{R}^{2}$ of more than 0.99 in all steps shows the successful development of daily basis shale proxy model. Figure 6 and Figure 7 show some examples of the comparison of reservoir simulation output for daily gas production rate (Mscf/day) with the predicted one by the proxy model for some of the clusters as well as some of the laterals.

In all the plots blue dots represent the daily gas rate generated by the numerical simulator and the solid red line is the result from the pattern recognition-based shale proxy model. The results are self-descriptive enough to show the capability of developed proxy model in predicting the daily gas production profile for each hydraulic fracture cluster as well as lateral for the first two months of production. Moreover, the predicted production rate at cluster level can be accounted as synthetic PLT log (Production Logging Tool) at each time step to show the contribution of each cluster on flow. 


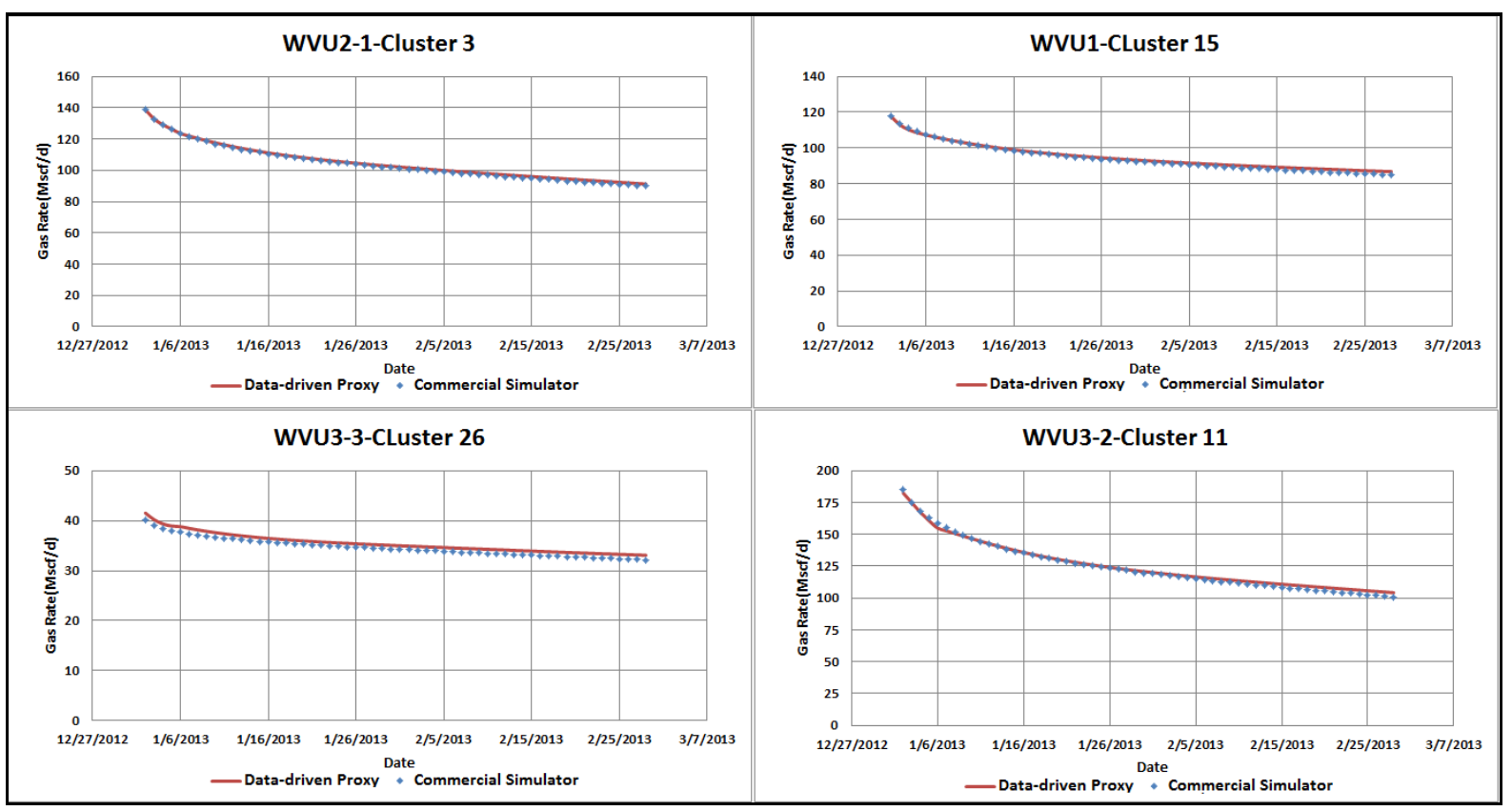

Figure 6 Daily gas production comparison- Results from the simulator and shale proxy model for some of the clusters

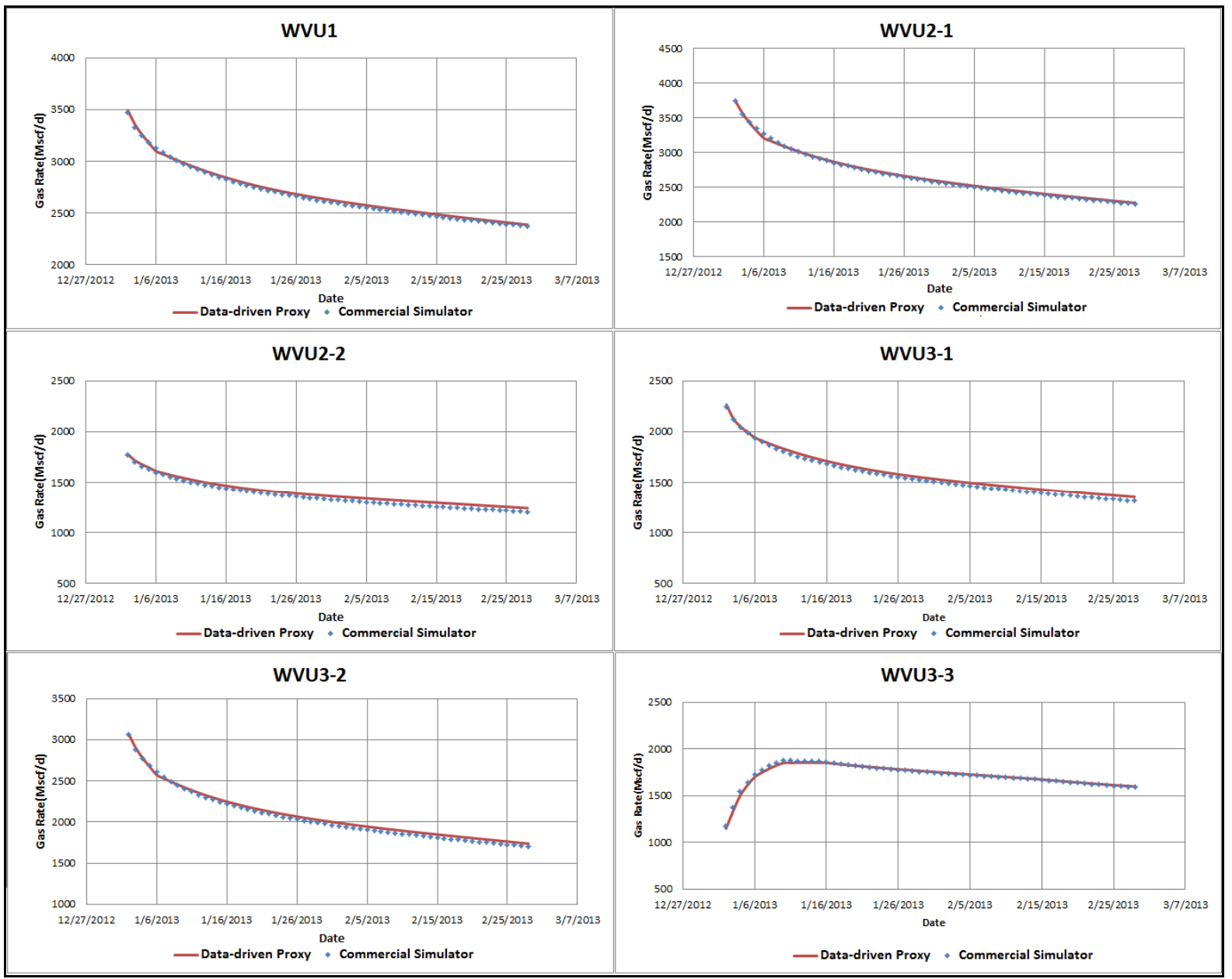

Figure 7 Daily gas production comparison- Results from the simulator and shale proxy model for some of the laterals 


\section{Second Pattern Recognition-based Shale Proxy Model (Monthly-basis)}

Second data-driven proxy model is developed to re-generate the monthly gas rate production (Mscf/m) for the first five years of production using the training database with 101,400 pairs of input-output.

The same procedure for building the first proxy (daily basis) is followed here. In order to understand the effect of each parameter on monthly gas rate (for the first five years), Key Performance Indicator (KPI) analysis is performed. According to this analysis, production time, natural fracture permeability, flowing bottomhole pressure as well as porosity are among the highest ranked parameters during five years of production.

It is interesting to see the hydraulic fracture cluster location, which accounts for the interference between the clusters and also sigma factor that control matrix to fracture flow as the second most important parameters. Alternatively, very low ranking of Langmuir volume and Langmuir pressure as well as diffusion coefficient and sorption time confirm the insignificant impact of sorption features on production performance for the first five years of production.

The cross plots showing the predicted (by neural network) and simulated (by numerical simulator) values of monthly gas flow rate (Mscf/month) for training, calibration and verification steps (from left to right) are shown in Figure 8. In these plots, x-axis corresponds to the neural network predicted gas rate and the y-axis shows the simulated gas rate by the numerical simulator.

In all the steps (training, calibration and verifications), $\mathrm{R}^{2}$ of more than 0.99 shows the successful development of monthly basis shale proxy model. Figure 9 and Figure 10 show some examples of the comparison of reservoir simulation output for monthly gas production rate with the predicted one by proxy model for some of the clusters as well as some of the laterals.
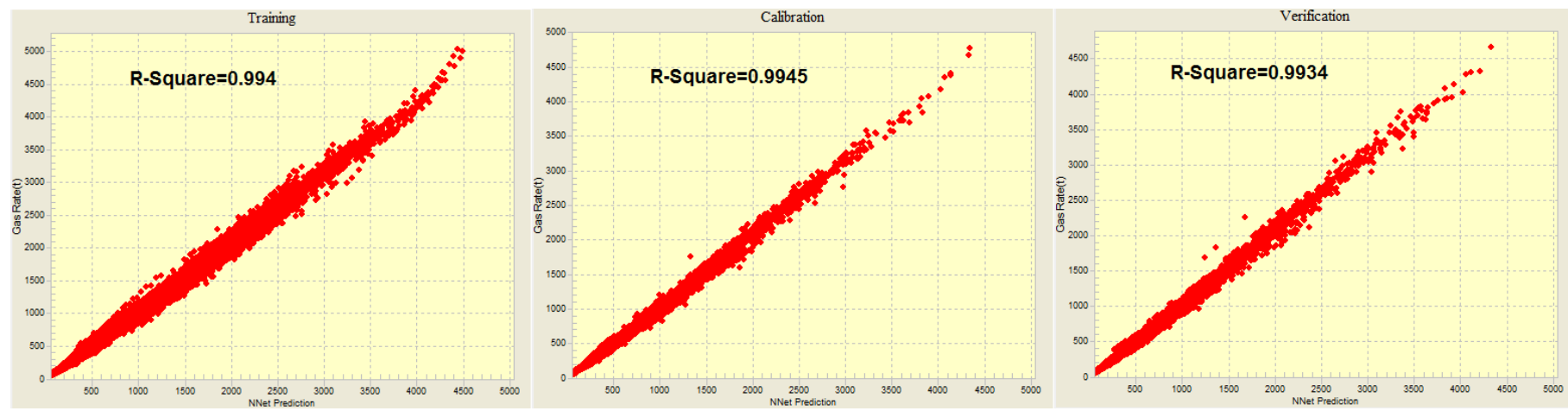

Figure 8.NN training, calibration and validation results (From left to right relatively)-Monthly proxy model 


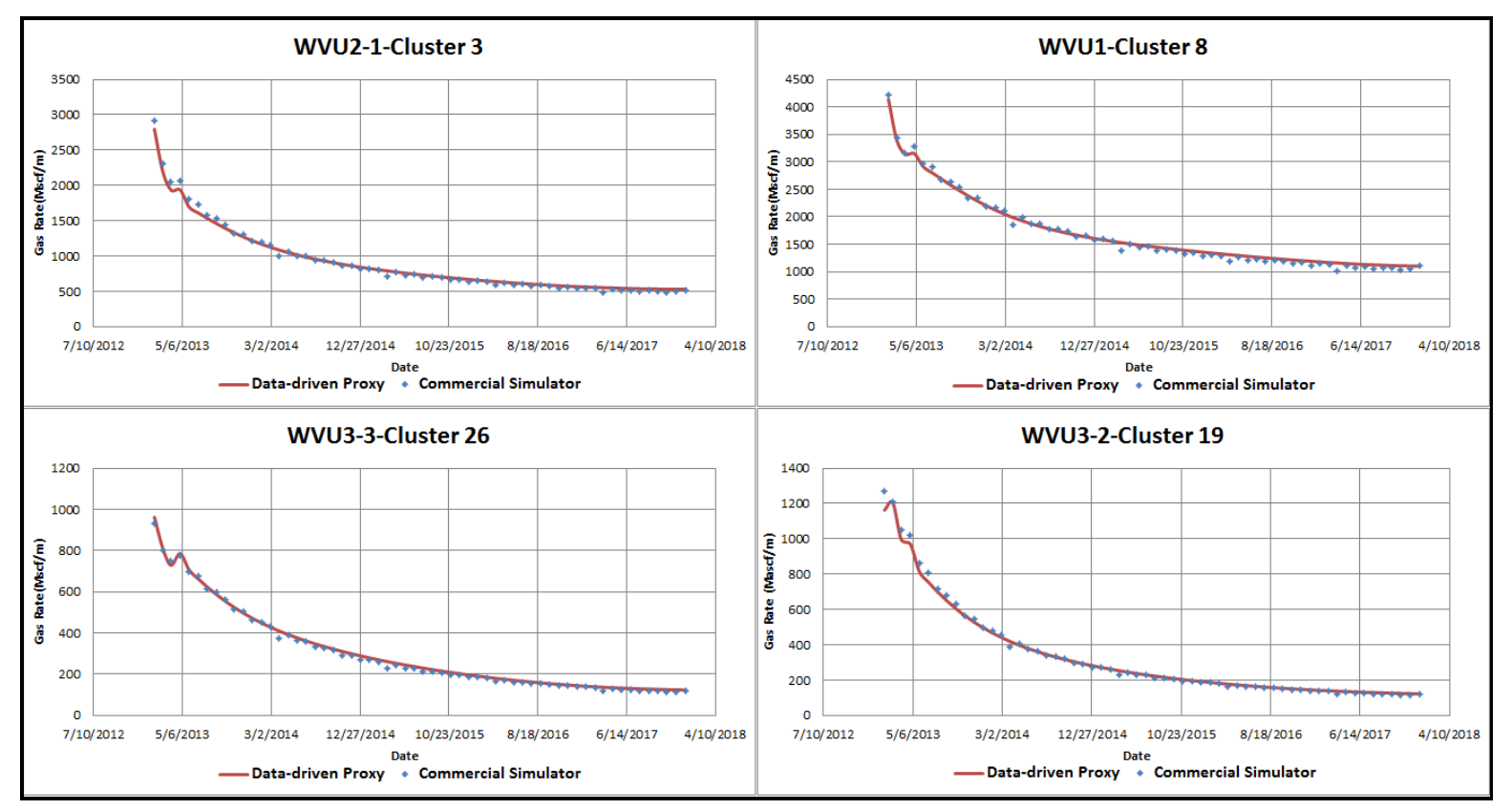

Figure 9 Monthly gas production comparison- Results from the simulator and shale proxy model for some of the clusters

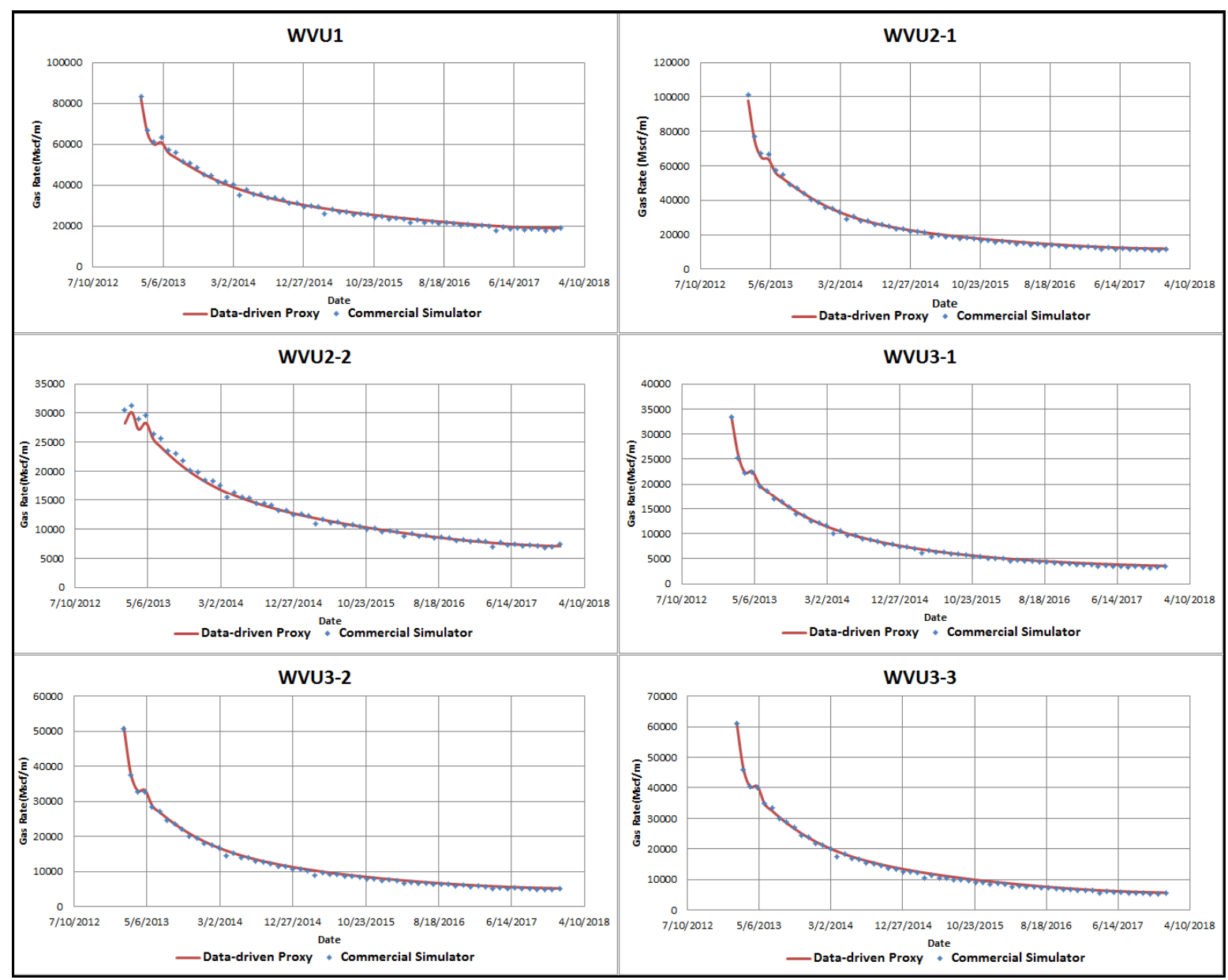

Figure 10 Monthly gas production comparison- Results from the simulator and shale proxy model for some of the laterals 


\section{Third Pattern Recognition-based Shale Proxy Model (Yearly-basis)}

The descriptive spatio-temporal database with 169,000 pairs of input-output is used to develop the third shale proxy model which is able to predict the annual gas rate production (Mscf/year) for 100 years. Production time, sorption time, Langmuir isotherm, natural fracture and matrix permeability and NTG are ranked as the most influential parameters on 100 years production performance of shale gas well.
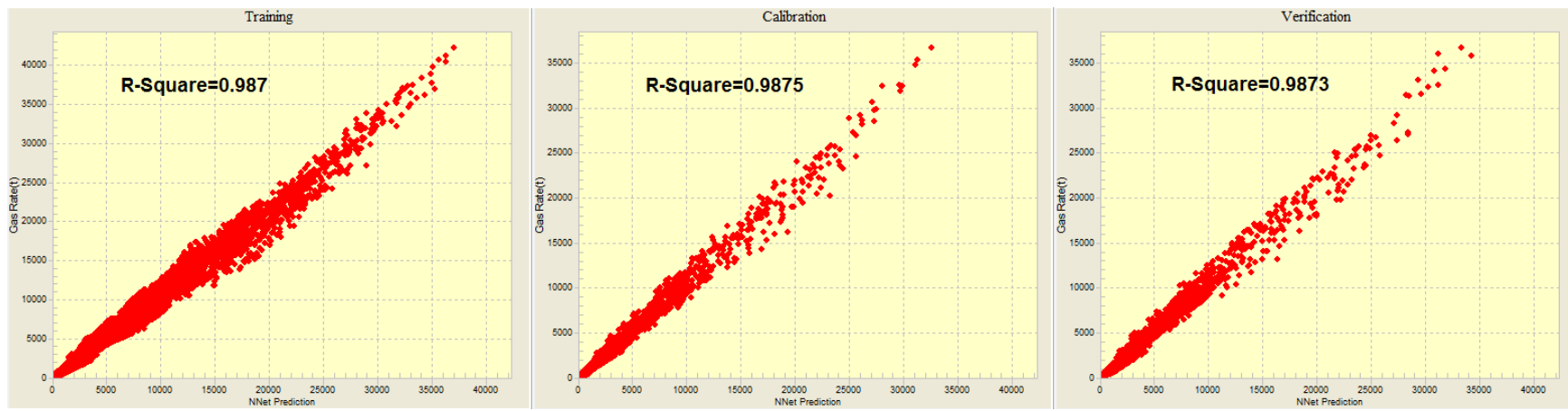

Figure $11 \mathrm{NN}$ training, calibration and verification results (From left to right relatively)-Yearly proxy model

Figure 11 illustrates the cross plots comparing simulated (by numerical simulator) and predicted (by NN) annual gas production rate (Mscf/year) for training, calibration and verification steps (from left to right).In these plots, $\mathrm{x}$-axis corresponds to the neural network predicted gas rate and the y-axis shows the simulated gas rate by the numerical simulator. The calculated $\mathrm{R}^{2}$ for training, calibration and verification results are around 0.99 .

Several examples of the comparison of reservoir simulation output for annual gas production rate with the predicted one by developed proxy model for some of the clusters and the laterals are shown in Figure 12 and Figure 13. In all the plots, blue dots represent the annual gas rate generated by the numerical simulation model, while the solid red line demonstrates the proxy model result.

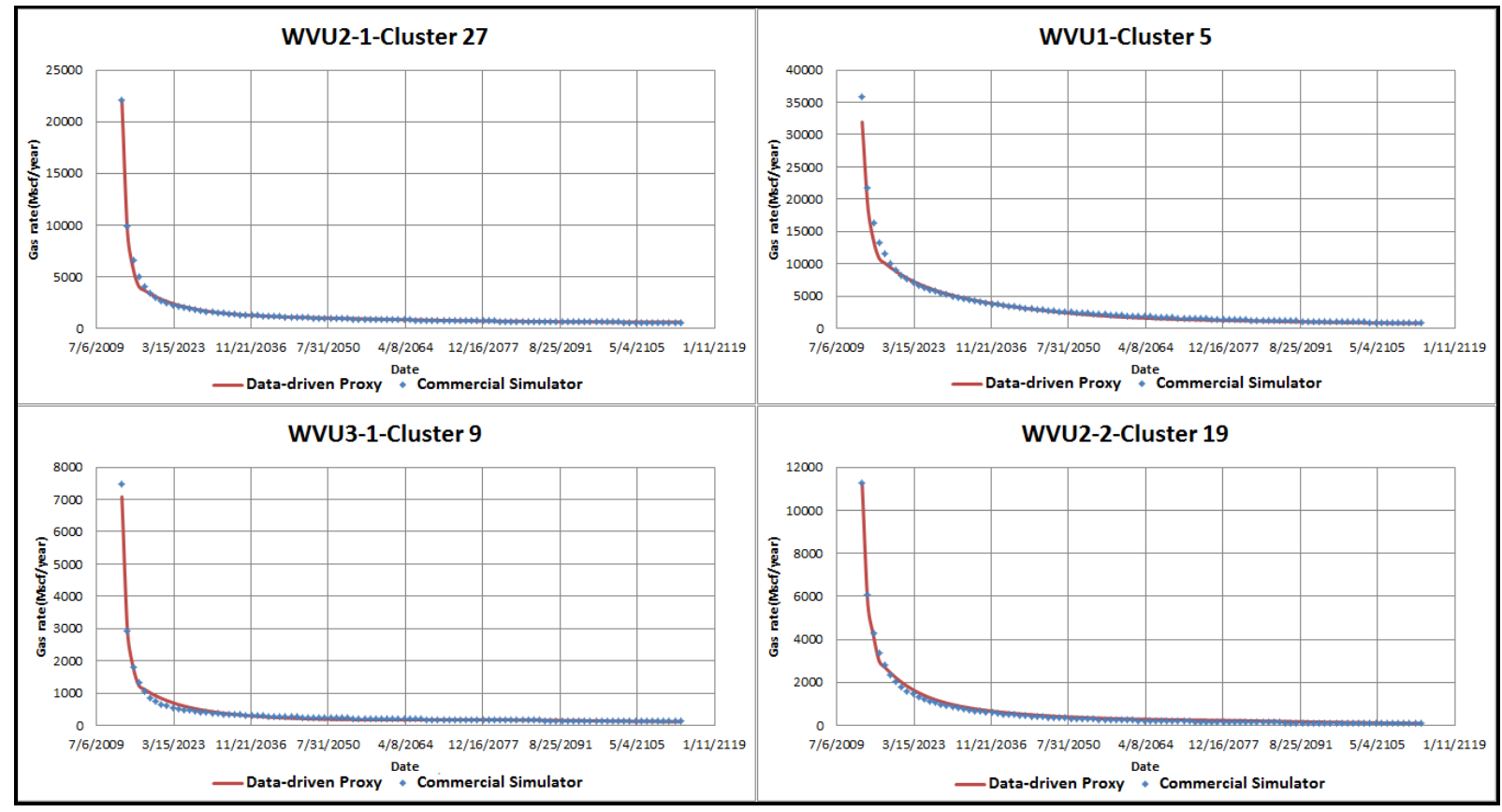

Figure 12 Annual gas production comparison- Results from the simulator and shale proxy model for some of the clusters 


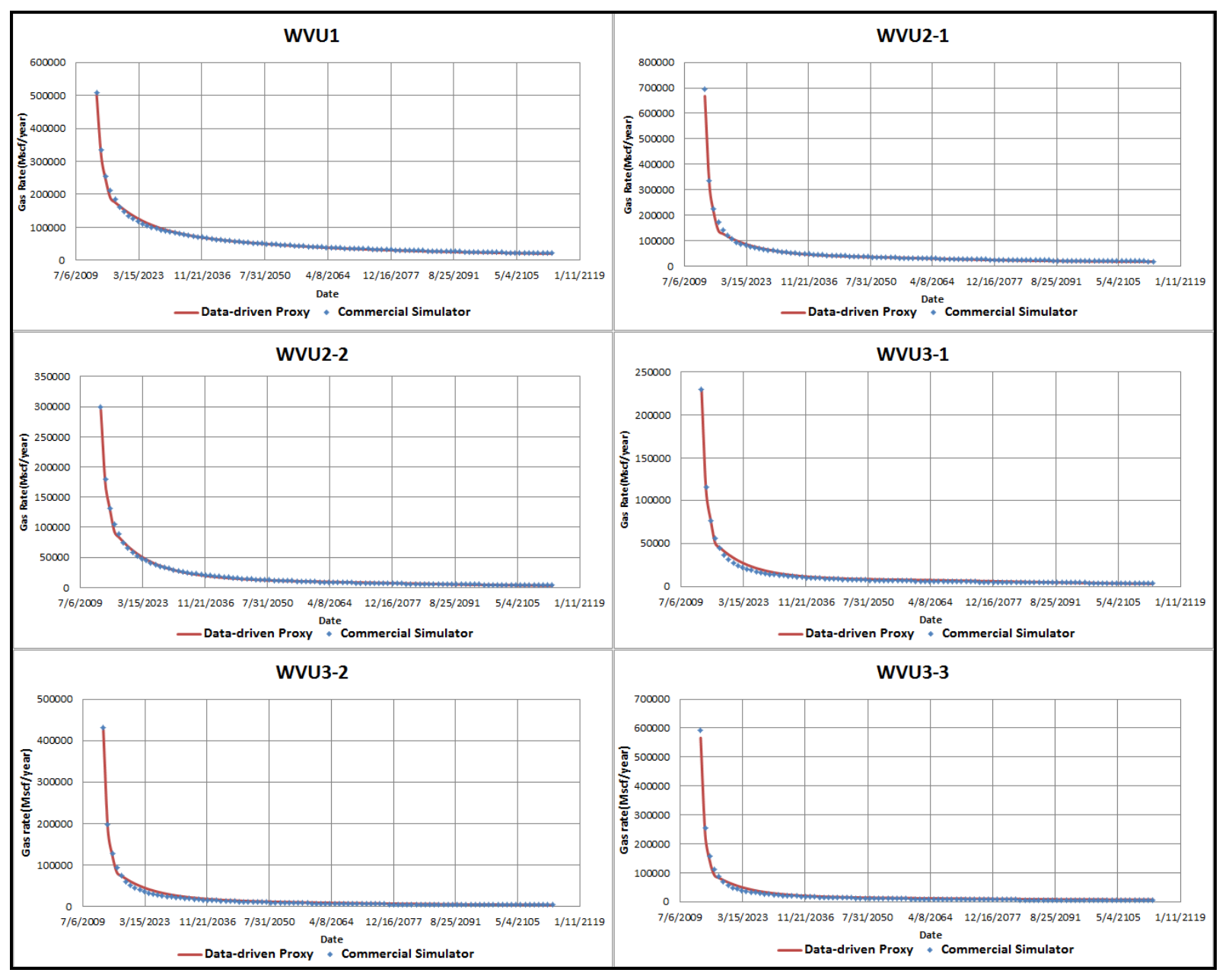

Figure 13 Annual gas production comparison- Results from the simulator and shale proxy model for some of the laterals

As illustrated in Figure 12 and Figure 13, pattern recognition-based proxy model is successfully re-generated yearly gas rate production profile (Red solid line) by a commercial numerical simulator (Blue dots) for the 100 years of production at cluster and lateral level.

The only problem that can be observed in almost all the cases is that the developed proxy model for yearly production could not capture the transient behavior that is happening during the first five years of production. In order to address this problem, monthly and annual based shale proxies are combined. In other word, the first five years of production in annual proxy is replaced by the corresponding values that are already generated by monthly proxy model. In this case, the results are improved significantly.

Figure 14 and Figure 15 show this improvement for four clusters as an example (Figure 14 ) and the whole WVU2-2 lateral as well (Figure 15). 


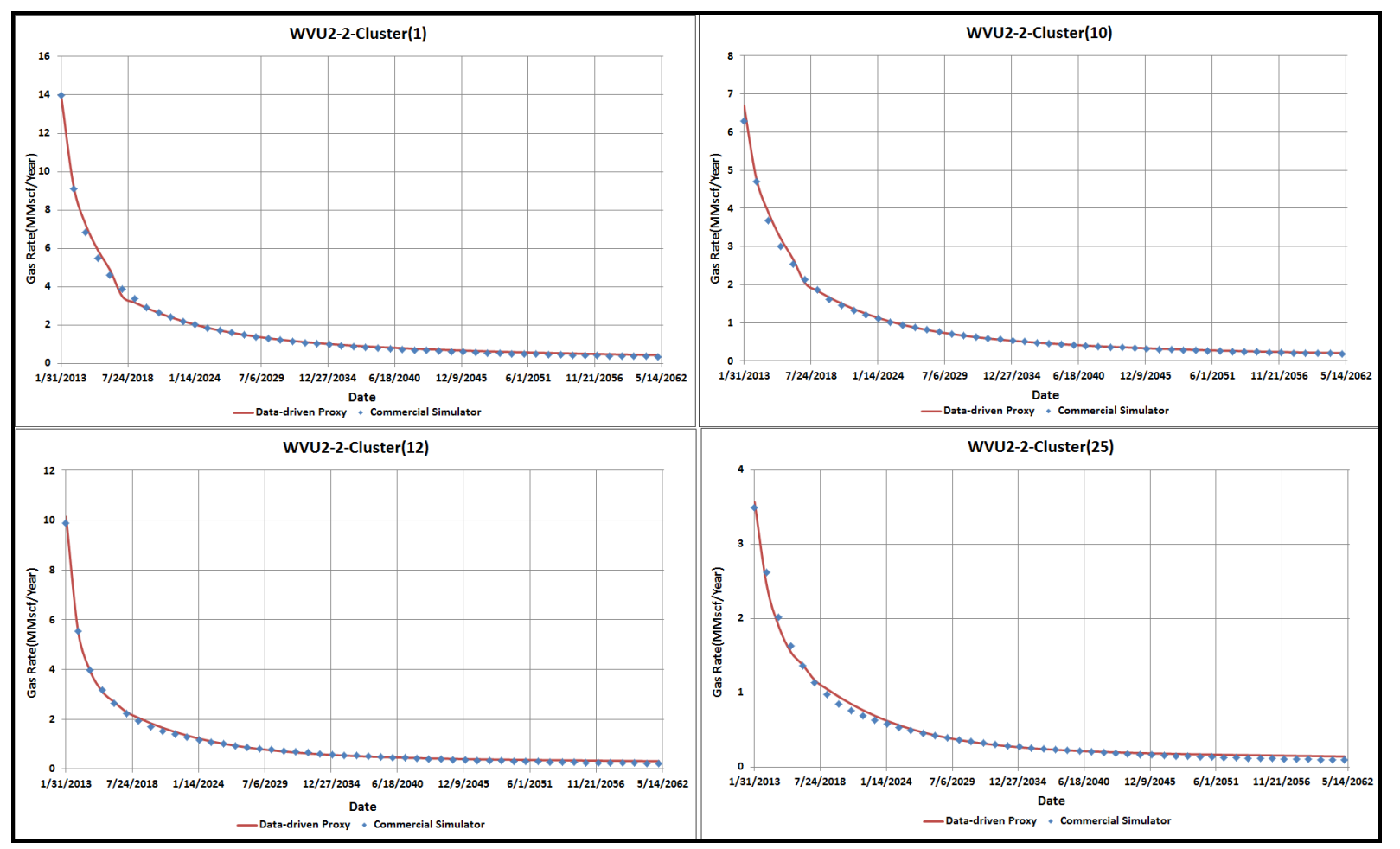

Figure 14 Combined monthly and yearly proxies- Yearly gas rate production for four clusters located in WVU-2-2 lateral

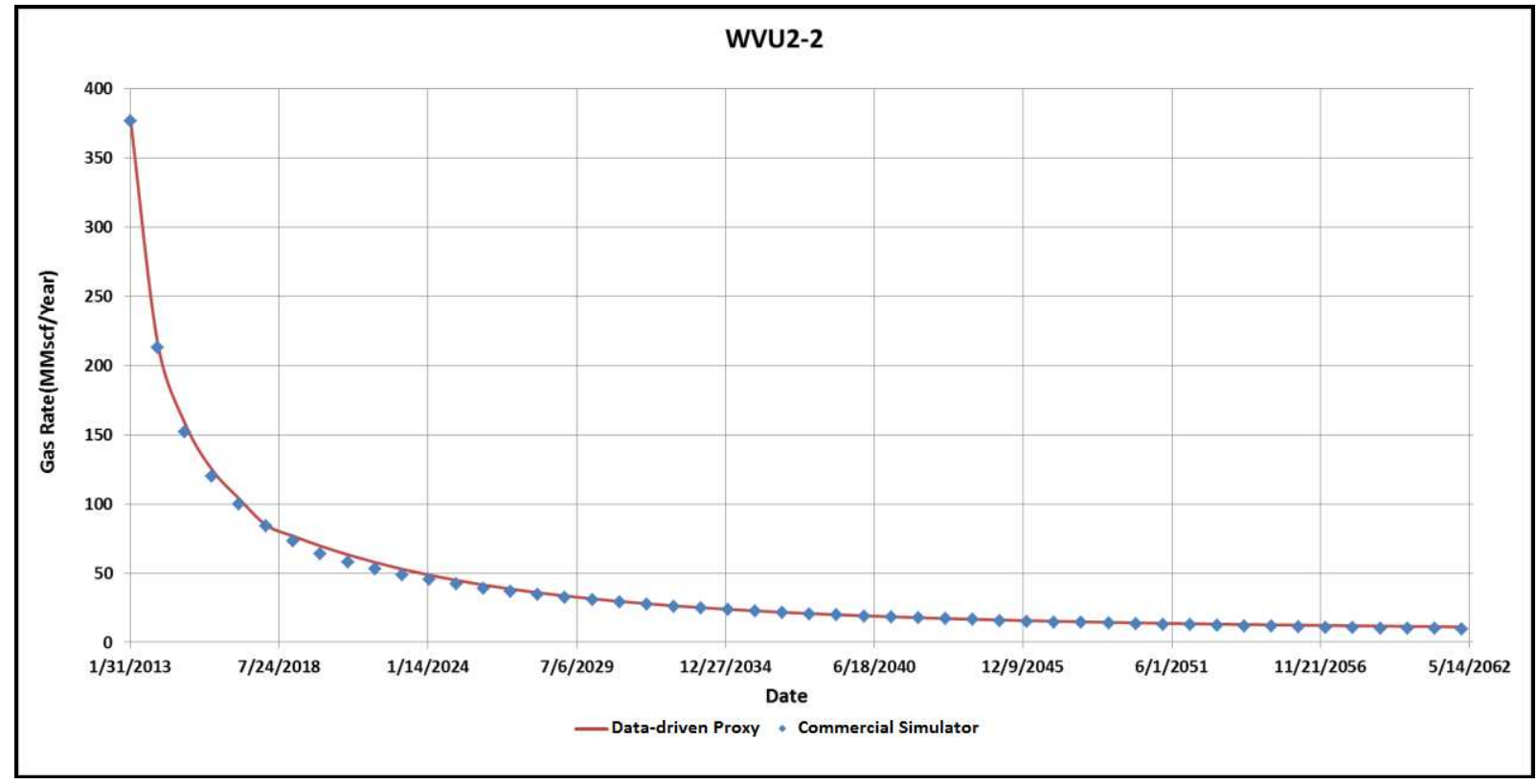

Figure 15 Combined monthly and annual proxies- Annual gas rate production WVU-2-2 lateral

\section{Pattern Recognition-based Proxy Models Validation by a Blind Case}

During pattern recognition-based proxy models development, some of the data were not included in the training set and used for calibration and verification purpose. Nevertheless, in order to perform additional test to examine the 
predictive capability of the developed shale proxy models, a new simulation run with the uncertainty domain is designed that is completely different from the previous runs, which were used during proxy model development process (Training, calibration and primary validation).

Figure 16 shows the predictive capability of the developed proxy models. In this figure the blind simulated gas production rates (Blue dots) for different time resolutions of daily, monthly and yearly (from top to bottom) are compared with the shale proxy models (Red lines) for WVU1 lateral. Good results confirm the robustness of developed shale proxy models to mimic the simulation behavior and can be used to generated thousands of production profiles with different time resolutions for detailed and quick uncertainty assessment which is almost impossible to perform such analysis with using only numerical reservoir simulation.

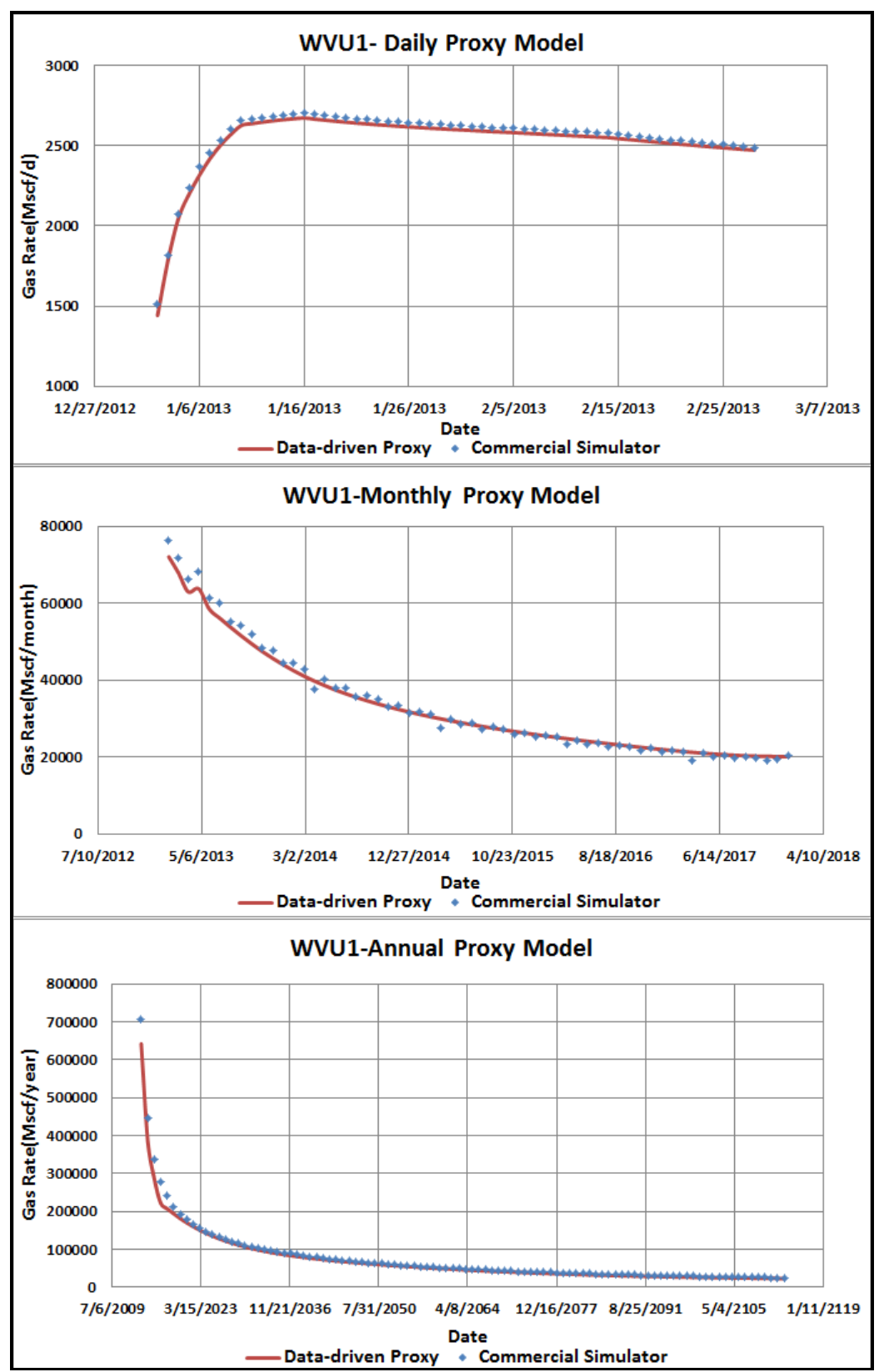

Figure 16 Data-driven proxy models validation using blind run for WVU1 for different time resolutions of daily, monthly and annually( from top to bottom) 


\section{Summary and Conclusions}

In this paper, a Next-generation shale proxy model using machine learning is developed to address the underutilization of shale numerical simulation models in the case of using EHF technique. The developed pattern recognition-based proxy models preserve all the qualities that had gone into developing a complex shale model with explicit representation of massive hydraulic fractures, by not summarizing the numerical model but mimic its behavior.

Pattern recognition-based proxy models are developed to predict the contribution of each individual cluster on a daily, monthly and yearly basis with acceptable accuracy $(<15 \%$ error) and their capabilities in predictive mode are tested using a completely blind simulation run. The developed proxy models paired with the numerical simulation model can be used as an effective reservoir management tool by quick quantification of the uncertainties.

Because the proxies are developed at the HF cluster level, it is robust enough to predict the new well production profile with any definite number of hydraulic fractures and any assigned properties in uncertainty domain. And the last but not least, this technique can be used as an assisted history-matching tool. Since history matching of a multilateral pad with large number of hydraulic fractures is a tedious and labor intensive practice, the pattern recognition-based proxy model can be developed first to be used for tuning all the parameters until achieving the best history match result. The base simulation model (not history matched case) can be updated with the new set of tuned data that comes from the proxy model and the history match can be achieved much quicker.

\section{Acknowledgements}

The authors wish to acknowledge National Energy Technology Laboratory-RUA for supporting this project and also Intelligent Solutions, Inc. (ISI) and Schlumberger for providing the ISMA and Eclipse/ Petrel software packages.

\section{References}

Andrade, J., Civan, F., Devegowda, D., Sigal, R.”Accurate Simulation of Shale Gas Reservoirs" SPE135564. Annual Technical Conference and Exhibition held in Florence, Italy, September 19-22, 2010.

Barenblatt, G. I., Zeltov, Y. P., and Kochina, I. "Basic concepts in the theory of seepage of homogeneous liquids in fissured rocks" PMM (Journal of Soviet Applied Mathematics and Mechanics), 24(5): 1286-1303(1960).

Beskok, A., Karniadakis, G. E. "A model for flows in channels, pipes, and ducts at micro and nano scales" Microscale Thermophys Eng. 3(1), 43-77(1999).

Blaskovich, F.T., Gain, G.M., and Sonier, F., "A multi-component isothermal system for efficient reservoir simulation, SPE 11480, Middle East Oil Technical Conference, Bahrain, March 14-17, 1983.

Cipolla, C.L., Lolon, E.P., Erdle, J.C., and Rubin, B. "Reservoir Modeling in Shale-Gas Reservoirs" SPE Res. Eval. \& Eng. 13 (4): 638-653 (2010)

Civan, F. "Effective correlation of apparent gas permeability in tight porous media" Transport in Porous Media, 2010. Vol.82:375-384.

Clarkson, C. R., Ertekin, T. "A new model for shale gas matrix flow using the dynamic-slippage concept" AAPG Hedberg Conference, Austin, Texas, December 5-10, 2010

Dean, R.H. and Lo, L., "Development of a naturally fractured reservoir simulator and examples of its use" SPE 14110, International Meeting on Petroleum Engineering, Beijing, China, March 17-20,1986.

deSwaan-O, A. "Analytic solutions for determining naturally fractured reservoir properties by well testing" SPE Journal (June 1976) 117-122; Trans., AIME 261.

Ertekin, T., King, G. R., Schwerer, F. C.’Dynamic gas slippage: a unique dual-mechanism approach to the flow of gas in tight formations" SPE Formation Evaluation, 1(1): 43-52. SPE 12045-PA doi: 10.2118/12045-PA (1986) 
Eshkalak, M.O., Aybar, U., Sepehroori, K. :" An integrated reservoir model for unconventional resources, coupling pressure dependent phenomena" SPE 171008, SPE Eastern Regional Meeting, Charleston, WV, 21-23 October, 2014.

Eshkalak, M.O., Aybar, U., Sepehroori, K. "An Economic Evaluation on the Re-fracturing Treatment of the U.S. Shale Gas Resources” SPE 171009, SPE Eastern Regional Meeting, Charleston, WV, 21-23 October, 2014.

Eshkalak, M.O., Mohaghegh, S.D., Esmaili, S., 2013. Synthetic, geomechanical logs for Marcellus shale. In: Paper SPE 163690 Presented at the SPE Digital Energy Conference and Exhibition Held in Woodlands, Texas, USA.

Hill, A.C. and Thomas G.W."A new approach for simulating complex fractured reservoirs", SPE 13537, SPE Reservoir Simulation Symposium, Anaheim, CA, February 10-13(1985)

Hudson, J., Civan, F., Michel, V. G., Devegowda, D., Sigal, R.” Modeling multiple-porosity transport in gas-bearing shale formations" SPE-153535, SPE Latin American and Caribbean Petroleum Engineering Conference ,Mexico City, Mexico, SPE, April 16-18,2012

Hudson, J. "Quad-porosity model for description of gas transport in shale-gas reservoirs". MS thesis, Oklahoma U., Norman, Oklahoma, 2011.

Jang, J.S.R. \& Sun, C.T. "Neuro-fuzzy modeling and control” In The Proceeding of the IEEE, vol. 83, 378-406. (1995).

Javadpour, F. "Nanopores and apparent permeability of gas flow in mudrocks (shales and siltstone)". J. of Canadian Petroleum Tech., v. 48, pp 16-21(2009)

Kalantari-Dahaghi .A, Esmaili.S, Mohaghegh. S:”Fast Track Analysis of Shale Numerical Models” SPE 162699, Canadian Unconventional Resources Conference held in Calgary, Alberta, Canada, 30 October-1 November 2012.

Kazemi, H.'Pressure transient analysis of naturally fractured reservoirs with uniform fracture distribution" SPE Journal, 9(4):451-462 (1969)

Mohaghegh. S, Abdull,F :" Production Management Decision Analysis Using AI-Based Proxy Modeling of Reservoir Simulations - A Look-Back Case Study" SPE 170664, SPE Annual Technical Conference and Exhibition held in Amsterdam, The Netherlands, 27-29 October 2014.

Nauck, D. "Neuro-fuzzy systems: Review and prospects" In Fifth European Congress on Intelligent Techniques and Soft Computing (EUFIT97), 1044-1053. (1997).

Rossen, R.H., "Simulation of naturally fractured reservoir with semi-implicit source terms" SPE Journal, 201-210, June 1977.

Rubin, B: “Accurate Simulation of Non-Darcy Flow in Stimulated Fracture Shale Reservoirs," SPE 132293 prepared for presentation at the Western Regional Conference held in Anaheim, CA, May 27 - 29, 2010

Saidi, A.M."Simulation of naturally fractured reservoirs" SPE 12270, Reservoir Simulation Symposium, San Francisco, CA, November 15-18, 1983.

Shabro, V., Torres-Verdin, C., and Javadpour, F."Numerical simulation of shale-gas production: from pore-scale modeling of slip-flow, Knudsen diffusion, and Langmuir desorption to reservoir modeling of compressible fluid" SPE 144355, North American Unconventional Gas Conference and Exhibition in the Woodlands, Texas, USA, June14-16, 2011

Shabro, V., Torres-Verdin, C., and Sepehrnoori, K. "Forecasting gas production in organic shale with the combined numerical simulation of gas diffusion in kerogen, Langmuir desorption from kerogen surfaces, and advection in nanopores" SPE-159259, Annual Technical Conference and Exhibition held in San Antonio, Texas, USA, October 8-10, 2012.

Suliman B., Meek R., Hull R., Bello H., Portis D., and Richmond P.” Variable Stimulated Reservoir Volume (SRV) Simulation: Eagle Ford Shale Case Study" SPE 164546, SPE Unconventional Resources Conference-USA held in The Woodlands, Texas, USA, 10-12 April 2013. 
Wilson, K. C., Durlofsky, L. J.” Computational Optimization of Shale Resource Development Using ReducedPhysics Surrogate Models" SPE 152946, SPE Western Regional Meeting, 21-23 March 2012, Bakersfield, California, USA

Yan. B, Wang. Y, Killough J. E." Beyond Dual-Porosity Modeling for the Simulation of Complex Flow Mechanisms in Shale Reservoirs" SPE 163651, SPE Reservoir Simulation Symposium held in The Woodlands, Texas USA, 18-20 February 2013.

Ziarani, A. S., Aguilera, R.” Knudsen's permeability correction for tight porous media” Transport in Porous Media, Vol.91: 239-260. (2012) 